\title{
Crystal Growth Techniques for Layered Superconductors
}

\author{
Masanori Nagao \\ Center for Crystal Science and Technology, University of Yamanashi, 7-32 Miyamae, Kofu, \\ Yamanashi 400-8511, Japan; mnagao@yamanashi.ac.jp \\ Academic Editors: Yoshikazu Mizuguchi and Antonio Bianconi \\ Received: 23 August 2017; Accepted: 16 October 2017; Published: 16 October 2017
}

\begin{abstract}
Layered superconductors are attractive because some of them show high critical temperatures. While their crystal structures are similar, these compounds are composed of many elements. Compounds with many elements tend to be incongruent melting compounds, thus, their single crystals cannot be grown via the melt-solidification process. Hence, these single crystals have to be grown below the decomposition temperature, and then the flux method, a very powerful tool for the growth of these single crystals with incongruent melting compounds, is used. This review shows the flux method for single-crystal growth technique by self-flux, chloride-based flux, and HPHT (high-pressure and high-temperature) flux method for many-layered superconductors: high- $T_{\mathcal{C}}$ cuprate, Fe-based and $\mathrm{BiS}_{2}$-based compounds.
\end{abstract}

Keywords: flux method; incongruent melting compounds; solution growth; high- $T_{\mathrm{c}}$ cuprate superconductor; Fe-based superconductor; $\mathrm{BiS}_{2}$-based superconductor

\section{Introduction}

This review presents the single-crystal growth of high- $T_{\mathrm{c}}$ cuprate, Fe-based and $\mathrm{BiS}_{2}$-based superconductors as typical layered superconductors. These layered superconductors form many analogous compounds and show other interesting properties. Additionally, layered superconductors have high anisotropy. In order to reveal such intrinsic properties, their single crystals are necessary. However, layered superconductors are composed of multiple elements and they are incongruent melting compounds. This suggests that the growth of single crystals cannot use the melt-solidification process and, thus, the solution-growth process is necessary. During the single-crystal growth process, the temperature must be lower than the decomposition temperature of the layered superconductors. Hence, the flux method is useful for single-crystal growth of layered superconductors. In this review, the single-crystal growth technique for high- $T_{\mathrm{c}}$ cuprate, Fe-based and $\mathrm{BiS}_{2}$-based compounds using various fluxes are introduced.

\section{Single-Crystal Growth Techniques for Incongruent Melting Compounds}

In order to grow single crystals, their raw materials of layered superconductors have to become solution (liquid phase) below the decomposition temperatures of the products. The solvent of that solution (liquid phase) is called "flux". Flux plays a role as a solvent in the solution-growth process. Therefore, flux should be composed of low-melting compounds, such as metals, alkali chlorides, and other compounds with a eutectic composition. The conventional flux method, the traveling solvent floating-zone (TSFZ) method, the top-seeded solution growth (TSSG) method, and the high-pressure and high-temperature (HPHT) flux method are briefly explained in this chapter. The conventional flux method does not have to use a special apparatus, but obtained crystals are small. On the other hand, TSFZ and TSSG methods use special apparatuses which are expensive. However, these methods 
can grow large-sized crystals, and the HPHT flux method is necessary for single-crystal growth under high pressure.

\section{1. (Conventional) Flux Method}

There are two kinds of flux methods. The components of the flux are the elements in the products; this is called as "self-flux method". The other is the use of flux which does not include the same element in the products.

The flux and raw materials for target compounds are mixed using a mortar, and put in the crucible. The mixed powder is heated for the solution-growth process, and then the single crystals are obtained. Generally, oxide materials (e.g., high- $T_{\mathrm{c}}$ cuprate compounds) are heated in open atmosphere, and non-oxide materials (e.g., Fe-based and $\mathrm{BiS}_{2}$-based compounds) are performed in a closed atmosphere, such as sealed in a quartz tube in vacuum. Finally, the important point of flux selecti is the following: flux should not react with the target materials, and should be easily separated from the grown single crystals. Examples of single-crystal growth of a layered superconductor using the flux method are shown below.

\subsubsection{High- $T_{\mathrm{C}}$ Cuprate Superconductor}

Many compounds are reported as high- $T_{\mathrm{c}}$ cuprate superconductors. This review shows high- $T_{\mathrm{C}}$ cuprate of $\left(\mathrm{R}, \mathrm{A}_{\mathrm{e}}\right)_{2} \mathrm{CuO}_{4}\left(\left(\mathrm{R}, \mathrm{A}_{\mathrm{e}}\right)-214\right.$ phase) (R: rare earth element, $\left.\mathrm{A}_{\mathrm{e}}: \mathrm{Ba}, \mathrm{Sr}, \mathrm{Ce}\right)[1], \mathrm{RBa}_{2} \mathrm{Cu}_{3} \mathrm{O}_{x}(\mathrm{R}-123$ phase) [2], $\mathrm{Bi}_{2} \mathrm{Sr}_{2} \mathrm{Ca}_{n-1} \mathrm{Cu}_{n} \mathrm{O}_{x}(n=1: \mathrm{Bi}-2201, n=2: \mathrm{Bi}-2212, n=3: \mathrm{Bi}-2223$ phase) [3] single crystals. $\mathrm{CuO}-$ based (self-flux) or alkali chloride-based compounds are generally employed for flux in the single-crystal growth of high- $T_{\mathrm{C}}$ cuprate. Single crystals several millimeters $(\mathrm{mm})$ in size are obtained by the flux method.

When nominal compositions of precursors are $(\mathrm{La}, \mathrm{Sr})_{2} \mathrm{CuO}_{4}: \mathrm{CuO}=1: 4$ (molar ratio) and $\mathrm{YBa}_{2} \mathrm{Cu}_{3} \mathrm{O}_{\mathrm{x}}: \mathrm{CuO}=3: 2$ (molar ratio), (La,Sr)-214 and Y-123 single crystals are grown from CuO flux (self-flux) [4]. Another example is the growth of Y-123 single crystals using $7 \mathrm{BaCuO}_{2} 11 \mathrm{CuO}$ as a flux. $\mathrm{Y}-123$ single crystals are grown from the precursor of $\mathrm{Y}-123: 7 \mathrm{BaCuO}_{2} 11 \mathrm{CuO}=16: 9$ (molar ratio) [5]. In contrast, $\mathrm{Bi}-2212$ single crystals are obtained from the precursor of the cation ratio $\mathrm{Bi}: \mathrm{Sr}: \mathrm{Ca}: \mathrm{Cu}=$ 2:2:1:2 which are weighed from $\mathrm{Bi}_{2} \mathrm{O}_{3}, \mathrm{SrCO}_{3}, \mathrm{CaCO}_{3}$, and $\mathrm{CuO}$. This precursor is put in a crucible with a weight on the cover (cap), and then the precursor is melted for Bi-2212 single-crystal growth. The cation ratio of this precursor is the stoichiometric composition for Bi-2212, and their melt acts as flux (self-flux) [6].

Alkali chloride-based compounds are also useful for flux. Y-123 and Bi-2212 single crystals are grown using $\mathrm{KCl}$-based flux. The melting point of $\mathrm{KCl}$ is $776{ }^{\circ} \mathrm{C}$ although eutectic composition exists between $\mathrm{KCl}$ and $\mathrm{NaCl}$. Its composition is $\mathrm{KCl}: \mathrm{NaCl}=1: 1$ (weight ratio) and eutectic temperature is $657^{\circ} \mathrm{C}$. This eutectic composition $(\mathrm{KCl} / \mathrm{NaCl})$ has the advantage for the growth of single crystals by lowering the melting points. Y-123 single crystals with sizes of several millimeters (mm) are grown from 2 wt \% KCl/ NaCl added Y-123 raw materials [7]. In Bi-2212 single crystals, some reports show using only $\mathrm{KCl}$ for flux [8-10]. In one instance, much $\mathrm{KCl}$ flux is added in Bi-2212 raw materials for single-crystal growth, which nominal composition is Bi-2212: $\mathrm{KCl}=1: 99$ (weight ratio) [9].

Finally, I introduce the growth of single-crystalline whiskers. Whisker is a special morphology of the single crystal. They have high aspect ratio (needle shape) with perfect crystallinity. However, the growth mechanism is not completely clear. Growth of whiskers of high- $T_{\mathrm{c}}$ cuprate layered superconductors is reported [11]. Those growth methods use glassy precursor and/or special flux. High- $T_{\mathrm{c}}$ cuprate superconductors are composed of many elements. Therefore, growth of high crystallinity single crystals is difficult. However, the whiskers have perfect crystallinity, and are free of dislocation. Figure 1 shows a typical scanning electron microscope (SEM) image of a Y-123 single-crystal whisker. The growth method of high- $T_{\mathrm{c}}$ cuprate single crystal whiskers has two routes, which use a glassy precursor and a $\mathrm{TeO}_{2} / \mathrm{Sb}_{2} \mathrm{O}_{3}$-doped precursor. When using the glassy precursor method, $\mathrm{Al}_{2} \mathrm{O}_{3}$-doped $\mathrm{Bi}-2212$ raw materials are melted and quenched, thus, the glassy precursor 
(Bi-Sr-Ca-Cu-Al-O) is obtained. Bi-Sr-Ca-Cu-Al-O glassy precursor is heat-treated and then $\mathrm{Bi}-2212$ whiskers are grown on the precursor [11]. However, this method can grow only Bi-2212 whiskers in high- $T_{\mathrm{C}}$ cuprate superconductors. Whiskers of Bi-2212, Bi-2201, Bi-2223, and R-123 phases can be grown by $\mathrm{TeO}_{2} / \mathrm{Sb}_{2} \mathrm{O}_{3}$ doping method. For Bi-2212 and $\mathrm{Bi}-2201, \mathrm{TeO}_{2}$-doping and Ca-rich precursors are used for whisker growth of which nominal compositions are $\mathrm{Bi}_{2} \mathrm{Sr}_{2} \mathrm{Ca}_{n} \mathrm{Cu}_{n} \mathrm{Te}_{0.5} \mathrm{O}_{x}$ ( $n=1$ for Bi-2201, $n=2$ for Bi-2212). Those precursors are pressed into pellets and heated. Whiskers are obtained on the pellets [12,13]. $\mathrm{Bi}_{1.6} \mathrm{~Pb}_{0.4} \mathrm{Sr}_{2.0} \mathrm{Ca}_{2.0} \mathrm{Cu}_{3.0} \mathrm{O}_{x}$ single phase powder $(1.0 \mathrm{~mol})$ and $\mathrm{TeO}_{2}(0.5 \mathrm{~mol})$ are mixed and pelletized. This pellet is heated, and then ( $\mathrm{Bi}, \mathrm{Pb})-2223$ whiskers are obtained [14]. On the other hand, R-123 whiskers can also be grown from $\mathrm{TeO}_{2} / \mathrm{Sb}_{2} \mathrm{O}_{3}$ doped precursor pellets. TeO $\mathrm{O}_{2} \mathrm{Sb}_{2} \mathrm{O}_{3}$ doping and $\mathrm{R}$ and Ba-rich precursors $\left(\mathrm{R}_{1.5-2.0} \mathrm{Ba}_{3} \mathrm{Cu}_{3} \mathrm{Te}_{0.5} \mathrm{O}_{x}\right.$ or $\left.\mathrm{R}_{1.5-2.0} \mathrm{Ba}_{2.75} \mathrm{Cu}_{3} \mathrm{Sb}_{0.5} \mathrm{O}_{x}\right)$ are used and the same treatment is applied. R-123 with $\mathrm{R}=\mathrm{Y}, \mathrm{Sm}, \mathrm{Eu}, \mathrm{Gd}, \mathrm{Dy}, \mathrm{Ho}, \mathrm{Er}, \mathrm{Tm}$, and Yb whiskers can be grown from the precursor pellet [15-17]. Additionally, Ca-substituted R-123 with R = Y, La, Nd, Sm, $\mathrm{Eu}, \mathrm{Gd}$, Dy, Ho, Er, Tm, $\mathrm{Yb}$, and $\mathrm{Lu}$ whiskers are grown from $\mathrm{RBa}_{2-3} \mathrm{Cu}_{3} \mathrm{Ca}_{1.00-1.75} \mathrm{Te}_{0.5} \mathrm{O}_{x}$ precursor pellets [18-20]. We assume that $\mathrm{TeO}_{2}$ and $\mathrm{Sb}_{2} \mathrm{O}_{3}$ play a role as flux.

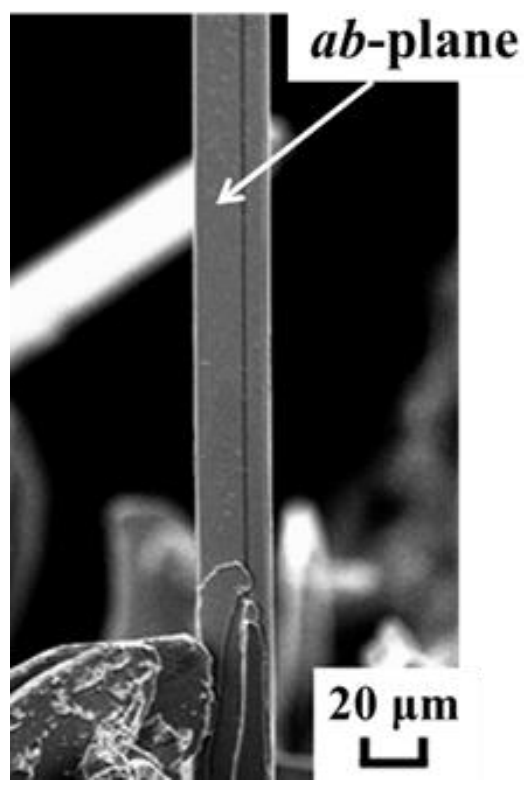

Figure 1. Typical SEM image of a Y-123 single crystal whisker.

\subsubsection{Fe-Based Superconductors}

Fe-based superconductors include $\mathrm{R}(\mathrm{O}, \mathrm{F}) \mathrm{FeAs}$ (1111) (R: rare earth elements) [21], $\mathrm{A}_{\mathrm{e}} \mathrm{Fe}_{2} \mathrm{As}_{2}$ (122) $\left(\mathrm{A}_{\mathrm{e}}\right.$ : alkaline earth metal) [22], AFeAs (111) (A: alkali metals) [23], $\beta$-FeSe (11) [24], and $\left(\mathrm{A}_{,} \mathrm{A}_{\mathrm{e}}\right)_{2} \mathrm{Fe}_{4} \mathrm{Se}_{5}$ (245) [25], Fe-based with perovskite oxide layer compounds (so-called 42622) [26], and so on. Some types of Fe-based superconductors are reported as single crystals which are grown by the flux method. Typical fluxes are As-based self-flux, Sn flux and chloride-based flux. Especially, growth of 122 single crystals have been intensively reported.

$\left(\mathrm{A}_{\mathrm{e}}, \mathrm{K}\right) \mathrm{Fe}_{2} \mathrm{As}_{2}\left(\mathrm{~A}_{\mathrm{e}}=\mathrm{Ba}, \mathrm{Sr}\right)$ single crystals can be grown using FeAs as a self-flux [27]. One of the growth methods is as follows. The starting materials of $\mathrm{Ba}$ or $\mathrm{Sr}, \mathrm{K}$, and FeAs in a molar ratio of 0.5:1:4 are put into an alumina crucible and sealed in a welded Ta crucible under $1.6 \mathrm{~atm}$ of Ar. This product is sealed in an evacuated quartz ampoule and is heated for the growth of single crystals [28]. In addition to the growth of $\mathrm{KFe}_{2} \mathrm{As}_{2}$ single crystals [29], $\mathrm{Ba}_{0.6} \mathrm{~K}_{0.4} \mathrm{Fe}_{2} \mathrm{As}_{2}$ single crystals are obtained from a stoichiometric compound, which plays a role of self-flux [30].

Growth of 111 single crystals can also be applied to the growth of $\mathrm{LiFeAs}$ and $\mathrm{NaFe}_{1-x} \mathrm{Co}_{x} \mathrm{As}$ $(x=0-0.3)$. In LiFeAs, Li metal added Fe-As mixture is placed into an $\mathrm{Al}_{2} \mathrm{O}_{3}$ crucible. The crucible is inserted into the $\mathrm{Nb}$ container, covered by a $\mathrm{Nb}$ cap with outlets for the flux (for a sieve). $\mathrm{The} \mathrm{Nb}$ 
container is welded in an Ar atmosphere with a base pressure of $1.5 \mathrm{~atm}$, and the sealed $\mathrm{Nb}$ container is sealed in a quartz tube under $0.25 \mathrm{~atm}$ of Ar to prevent any oxidation. This product is heated for single-crystal growth. Figure 2 shows optical and SEM images of obtained LiFeAs single crystals [31]. On the other hand, $\mathrm{NaFe}_{1-x} \mathrm{Co}_{x} \mathrm{As}(x=0-0.3)$ single crystals are grown using $\mathrm{NaAs}$ self-flux. $\mathrm{NaAs}, \mathrm{Fe}$, and Co powders are weighed to the molar ratio of NaAs:Fe:Co $=4:(1-x): x$, and ground. The mixtures are put into $\mathrm{Al}_{2} \mathrm{O}_{3}$ crucibles, then sealed in iron crucibles under $1.5 \mathrm{~atm}$ of high-purity Ar gas. Then the crucible is heated for single-crystal growth [32].
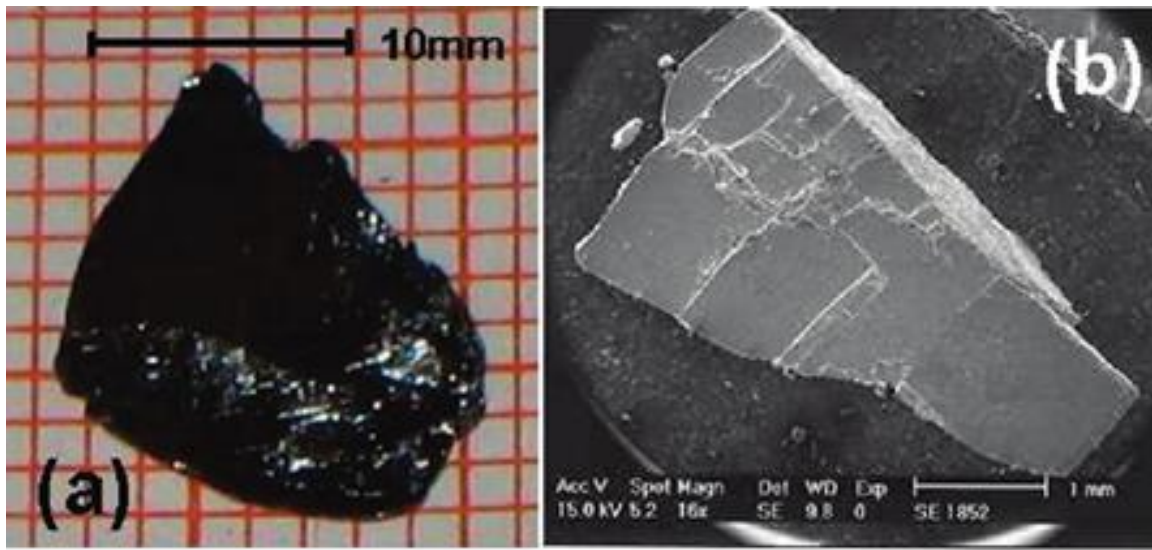

Figure 2. Optical image of a LiFeAs crystal (a) and a SEM image (b) [31]. Single-Crystal Growth and Characterization of Superconducting LiFeAs.

There are reports about the growth of $\mathrm{Sr}_{4} \mathrm{~V}_{2} \mathrm{O}_{6} \mathrm{Fe}_{2} \mathrm{As}_{2}$ single crystals, which is a FeAs self-flux method. The nominal composition of the raw materials is FeAs: $\mathrm{Sr}_{4} \mathrm{~V}_{2} \mathrm{O}_{6} \mathrm{Fe}_{2} \mathrm{As}_{2}=2: 1$ (molar ratio). The mixture is sealed in a quartz tube in vacuum, then heated [33]. Moreover, growth of nano-sized whiskers is reported. The $\mathrm{Ca}_{10}\left(\mathrm{Pt}_{4} \mathrm{As}_{8}\right)\left(\mathrm{Fe}_{1.8} \mathrm{Pt}_{0.2} \mathrm{As}_{2}\right)_{5}$ precursor with $10 \mathrm{wt} \%$ CaAs self-flux is put into a Ta capsule and sealed in a quartz tube in vacuum. This product is heated, and the $\mathrm{Ca}_{10}\left(\mathrm{Pt}_{4} \mathrm{As}_{8}\right)\left(\mathrm{Fe}_{1.8} \mathrm{Pt}_{0.2} \mathrm{As}_{2}\right)_{5}$ nano-sized whiskers are obtained. SEM images are shown in Figure 3. The whiskers have lengths of $0.1-2.0 \mathrm{~mm}$, widths of $0.4-5.0 \mu \mathrm{m}$, and thicknesses of 0.2-1.0 $\mu \mathrm{m}$ [34].
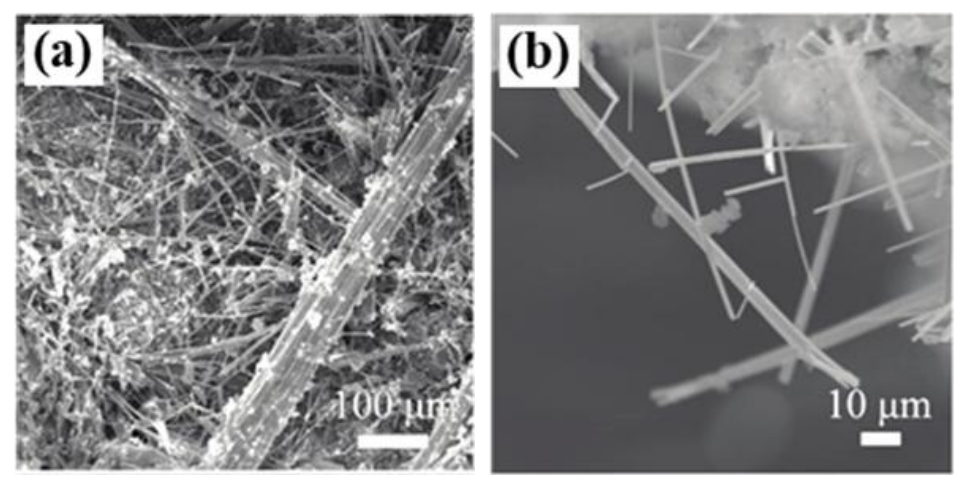

Figure 3. $\mathrm{SEM}$ images of $\mathrm{Ca}_{10}\left(\mathrm{Pt}_{4} \mathrm{As}_{8}\right)\left(\mathrm{Fe}_{1.8} \mathrm{Pt}_{0.2} \mathrm{As}_{2}\right)_{5}$ whiskers [34]. Growth of Single-Crystal $\mathrm{Ca}_{10}\left(\mathrm{Pt}_{4} \mathrm{As}_{8}\right)\left(\mathrm{Fe}_{1.8} \mathrm{Pt}_{0.2} \mathrm{As}_{2}\right)_{5}$ Nanowhiskers with Superconductivity up to $33 \mathrm{~K}$. (a) Wide field of view, (b) Enlarged image.

Sn flux is also effective for 122 single-crystal growths, since $\mathrm{Sn}$ has a low melting point $\left(232{ }^{\circ} \mathrm{C}\right)$. $\mathrm{BaFe}_{2} \mathrm{As}_{2}$ and $\mathrm{Ba}_{0.55} \mathrm{~K}_{0.45} \mathrm{Fe}_{2} \mathrm{As}_{2}$ single crystals can be grown using $\mathrm{Sn}$ flux. $\mathrm{Ba}, \mathrm{K}, \mathrm{Fe}$, and As are added to $\mathrm{Sn}$ in the molar ratio of $\left(\mathrm{Ba} / \mathrm{K} \mathrm{Fe}_{2} \mathrm{As}_{2}: \mathrm{Sn}=1: 48\right.$ and put into $\mathrm{MgO}$ crucible. The crucible containing silica wool is placed on top of the growth crucible and these are sealed in a silica tube 
under approximately $0.33 \mathrm{~atm}$ of Ar. Then this silica tube is heated for single-crystal growth. Sn flux is decanted from the obtained single crystals at $500{ }^{\circ} \mathrm{C}$ [35]. Nevertheless, the remaining Sn at the single crystal surfaces is subsequently dissolved at room temperature for a few days in liquid $\mathrm{Hg}$. The obtained single crystals are heated for one hour at $190{ }^{\circ} \mathrm{C}$ in vacuum to evaporate the remaining traces of $\mathrm{Hg}$ [36].

Finally, growth of 11 ( $\beta$-FeSe) single crystals is exhibited, for which chloride-based flux is effective. $\beta$-FeSe decomposes into Fe and a hexagonal phase $\left(\alpha\right.$-FeSe) at $457^{\circ} \mathrm{C}$. This suggests that single-crystal growth has to be perform at low temperature (less than $457^{\circ} \mathrm{C}$ ). Therefore, the eutectic chloride composition is useful for flux. Some reports are shown in the following. A eutectic temperature of $\mathrm{LiCl}: \mathrm{CsCl}=29: 21$ (molar ratio) composition is $326^{\circ} \mathrm{C}$, which can use the flux for $11(\beta-\mathrm{FeSe})$ single-crystal growth. After the growth, this flux can be removed by water wash. 11 ( $\beta$-FeSe) single crystals are grown by $\mathrm{LiCl} / \mathrm{CsCl}$ flux [37]. The eutectic composition of $\mathrm{KCl} / \mathrm{AlCl}_{3}$ is also used for 11 ( $\beta$-FeSe) single-crystal growth [38]. $\mathrm{AlCl}_{3}$-based compositions have low eutectic temperature. However, their handling should be done carefully to prevent an explosion hazard. The eutectic temperature of $\mathrm{NaCl}: \mathrm{KCl}=1: 1$ (molar ratio) composition is higher than $\beta$-FeSe decomposition temperature, but $\beta$-FeSe single crystals are obtained by rapid cooling between the $\mathrm{NaCl} / \mathrm{KCl}$ eutectic temperature and room temperature [39].

\subsection{3. $\mathrm{BiS}_{2}$-Based Superconductors}

$\mathrm{BiS}_{2}$-layered superconductors include $\mathrm{Bi}_{4} \mathrm{O}_{4} \mathrm{~S}_{3}$ [40], $\mathrm{R}_{\mathrm{n}}(\mathrm{O}, \mathrm{F}) \mathrm{BiS}_{2}\left(\mathrm{R}_{\mathrm{n}}\right.$ : $\left.\mathrm{La}, \mathrm{Ce}, \mathrm{Pr}, \mathrm{Nd}, \mathrm{Yb}\right)$ [41-45], $\mathrm{A}_{\mathrm{b}} \mathrm{FBiS}_{2}\left(\mathrm{~A}_{\mathrm{b}}\right.$ : Sr, Eu) [46-48], (La,M)OBiS 2 (M: Ti, Zr, Hf, Th) [49], and $\mathrm{Eu}_{3} \mathrm{~F}_{4} \mathrm{Bi}_{2} \mathrm{~S}_{4}$ [50] and $\mathrm{Bi}(\mathrm{O}, \mathrm{F}) \mathrm{BiS}_{2}[51,52]$. Especially, $\mathrm{R}_{\mathrm{n}}(\mathrm{O}, \mathrm{F}) \mathrm{BiS}_{2}$ shows similarity to the crystal structure of superconducting $\mathrm{R}(\mathrm{O}, \mathrm{F}) \mathrm{FeAs}$ (1111) [21], and S-site can be substituted by Se, which also becomes superconductive [53]. In contrast, substitution of $\mathrm{Sb}$ in $\mathrm{Bi}$ sites depress superconductivity. Single crystals of those superconductors can be grown using alkali metal chloride flux. CsCl-based composition is extensively used as a flux for $\mathrm{R}_{\mathrm{n}}(\mathrm{O}, \mathrm{F}) \mathrm{BiS}_{2}$ single-crystal growth, since $\mathrm{CsCl}$ exhibits little reactivity to the quartz tube at high temperature. Figure 4 shows the reactivity between each alkali chloride $(\mathrm{LiCl}, \mathrm{NaCl}, \mathrm{KCl}$, $\mathrm{RbCl}, \mathrm{CsCl})$ and the quartz tube at high temperature $\left(80{ }^{\circ} \mathrm{C} 10 \mathrm{~h}\right)$. The quartz tube is slightly reacted to $\mathrm{CsCl}, \mathrm{RbCl}$, and $\mathrm{KCl}$. Furthermore, a melting temperature of $\mathrm{CsCl}\left(645^{\circ} \mathrm{C}\right)$ is lower than those of $\mathrm{RbCl}$ and $\mathrm{KCl}$, which is advantageous as a flux. This review focuses on growth of $\mathrm{R}_{\mathrm{n}}(\mathrm{O}, \mathrm{F}) \mathrm{BiS}_{2}$ single crystals using CsCl-based flux. A eutectic $\mathrm{CsCl} / \mathrm{KCl}$ flux with $\mathrm{CsCl}: \mathrm{KCl}=5: 3$ molar ratio (eutectic temperature: $616{ }^{\circ} \mathrm{C}$ ) is mainly used for $\mathrm{Rn}(\mathrm{O}, \mathrm{F}) \mathrm{BiS}_{2}$ single-crystal growth [54]. Concretely, raw materials of $\mathrm{R}_{\mathrm{n}}(\mathrm{O}, \mathrm{F}) \mathrm{BiS}_{2}$ with nominal composition $(0.8 \mathrm{~g})$ and the $\mathrm{CsCl} / \mathrm{KCl}$ flux $(5.0 \mathrm{~g})$ are mixed using a mortar, and then sealed in a quartz tube under vacuum $(\sim 10 \mathrm{~Pa})$. This mixed powder is heated for single-crystal growth, and then furnace-cooled to room temperature. The quartz tube is opened in air, and the flux is dissolved using distilled water. The remaining product is filtered. Therefore, $R_{n}(\mathrm{O}, \mathrm{F}) \mathrm{BiS}_{2}$ single crystals are obtained $[55,56]$. Figure 5 shows a typical SEM image of $\mathrm{R}_{n}(\mathrm{O}, \mathrm{F}) \mathrm{BiS}_{2}$ $\left(\mathrm{R}_{\mathrm{n}}=\mathrm{Nd}\right)$ single crystals. For comparison, F-free $\mathrm{R}_{\mathrm{n}} \mathrm{OBiS}_{2}$ single crystals are grown by $\mathrm{CsCl}$ flux $[57,58]$. Since the heat-treatment temperature for the growth of F-free single crystals is higher than that of $\mathrm{R}_{\mathrm{n}}(\mathrm{O}, \mathrm{F}) \mathrm{BiS}_{2}$, thus, the quartz tube corrosion from $\mathrm{KCl}$ is enhanced at high temperature. Review of $\mathrm{R}_{\mathrm{n}}(\mathrm{O}, \mathrm{F}) \mathrm{BiS}_{2}$ superconducting single crystals is available [59]. With another flux, a eutectic composition of $\mathrm{KCl}: \mathrm{LiCl}=3: 2$ (molar ratio) can use the flux for $\mathrm{R}_{\mathrm{n}}(\mathrm{O}, \mathrm{F}) \mathrm{BiS}_{2}$ single crystals. The molar ratio of $\mathrm{KCl} / \mathrm{LiCl}$ flux and $\mathrm{Nd}(\mathrm{O}, \mathrm{F}) \mathrm{BiS}_{2}$ raw materials is $\mathrm{KCl} / \mathrm{LiCl}: \mathrm{Nd}(\mathrm{O}, \mathrm{F}) \mathrm{BiS}_{2}=25: 1$. The heat-treatment for single-crystal growth is performed at a lower temperature, below $750-450{ }^{\circ} \mathrm{C}$ to prevent corrosion of a quartz tube [60]. $\mathrm{La}(\mathrm{O}, \mathrm{F}) \mathrm{BiSe}_{2}$ is similar compound for $\mathrm{La}(\mathrm{O}, \mathrm{F}) \mathrm{BiS}_{2}$; these single crystals are also obtained using $\mathrm{CsCl}$ flux. The weight ratio of raw materials and $\mathrm{CsCl}$ flux is same for $\mathrm{La}(\mathrm{O}, \mathrm{F}) \mathrm{BiS}_{2}$ case [61]. Moreover, $\mathrm{R}_{n}(\mathrm{O}, \mathrm{F}) \mathrm{SbS}_{2}$ are non-superconducting compounds, those single crystals can be grown by the same growth method used for $\mathrm{R}_{n}(\mathrm{O}, \mathrm{F}) \mathrm{BiS}_{2}$ [62]. 


\section{Elements}
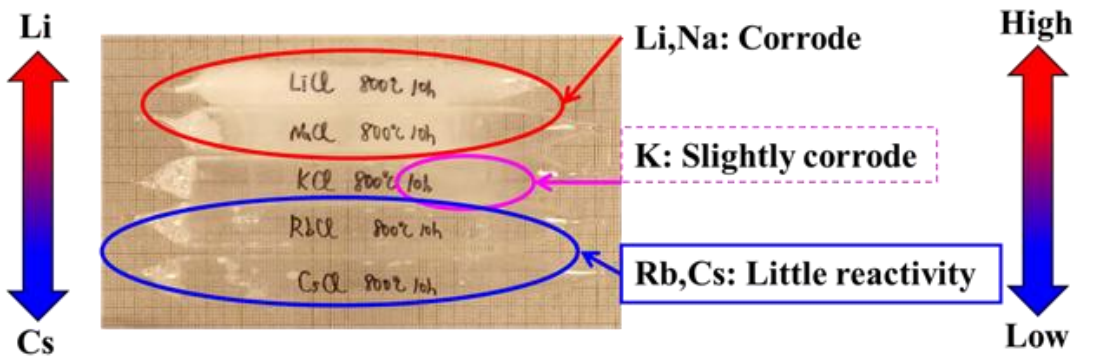

Figure 4. Reactivity between each alkali chloride ( $\mathrm{LiCl}, \mathrm{NaCl}, \mathrm{KCl}, \mathrm{RbCl}, \mathrm{CsCl})$ and quartz tube at 800 ${ }^{\circ} \mathrm{C}$ for $10 \mathrm{~h}$.

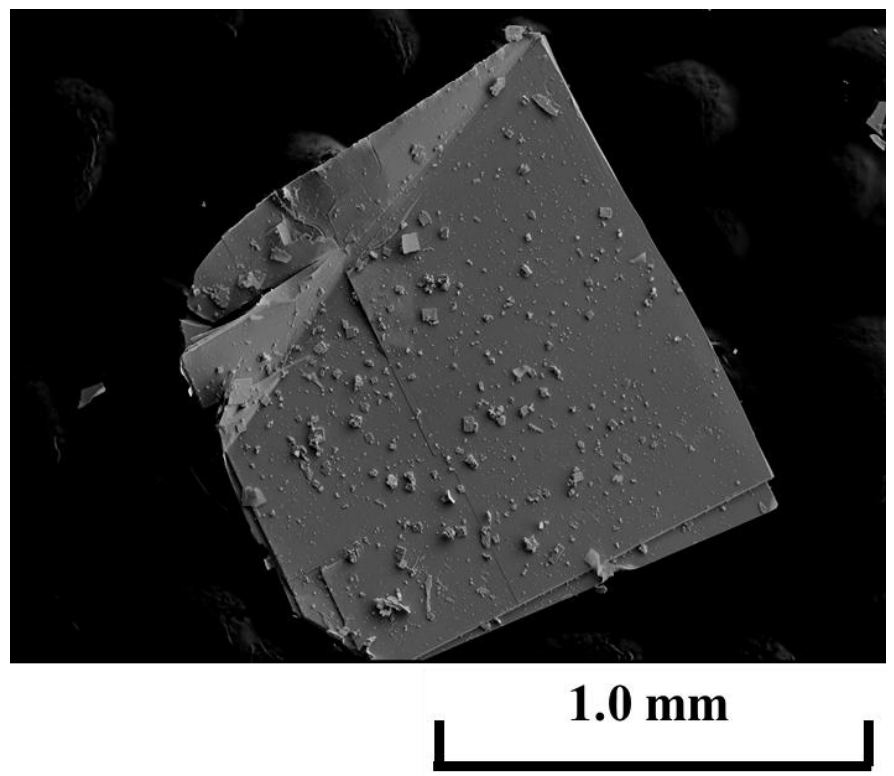

Figure 5. Typical SEM image of an $\mathrm{R}(\mathrm{O}, \mathrm{F}) \mathrm{BiS}_{2}(\mathrm{R}=\mathrm{Nd})$ single crystal.

\subsection{Traveling Solvent Floating-Zone (TSFZ) Method}

The traveling solvent floating-zone (TSFZ) method [63] is based on the floating-zone (FZ) method, which is one of the single-crystal growth methods for congruently melting compounds. This method does not use a crucible, which means that the reaction with a crucible does not need to be considered. The schematic image of the FZ method is shown in Figure 6a. The bottom of the feed rod and seed crystal are partially melted by the local heating, and the feed rod and seed crystal are connected via the melt by surface tension. Then, the molten zone is formed between the melt of the feed rod and the seed crystal. The feed rod and seed crystal move down for the single-crystal growth. In the TSFZ method, the solvent is welded to the bottom of the feed rod (Figure $6 b$ ). The solvent plays a role as flux. Figure 7 shows the typical phase diagram of incongruent melting. The target phase $(\alpha)$ becomes melts incongruently at $T_{d} \cdot \alpha$ cannot be grown by the simple melt growth, whereas the composition on $X-Y$ liquidus line $\left(\beta_{1}\right.$ to $\left.\beta_{2}\right)$ is selected for the solvent, and the liquid/melt of $\beta$ is slowly cooled, just below the $X-Y$ liquidus line, it begins to freeze into a crystal of $\alpha$ [64]. In other words, a feed rod is dissolved in the molten zone with the solvent, and then the feed rod becomes a liquid solution below the incongruent melting temperature. Subsequently, it is slowly cooled and the single crystal of the incongruent melting compound is obtained. 


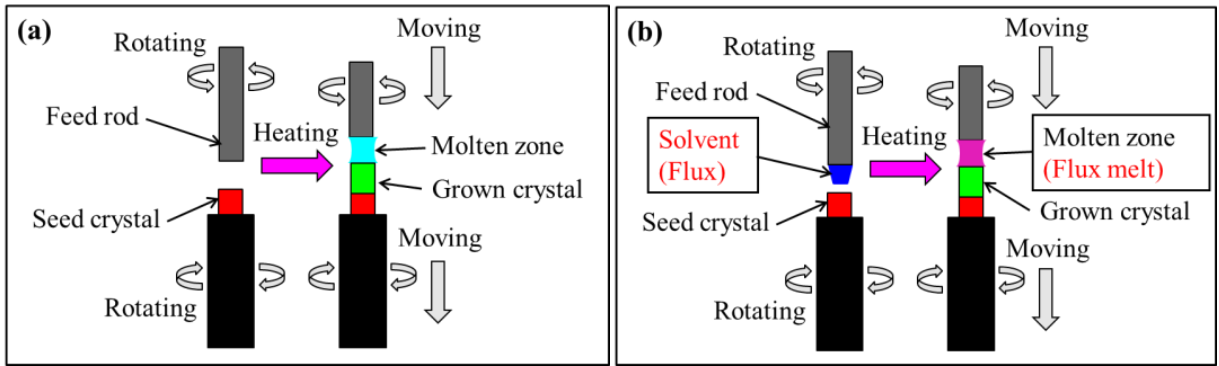

Figure 6. Schematic image of (a) floating zone (FZ) and (b) traveling solvent floating zone (TSFZ) methods.

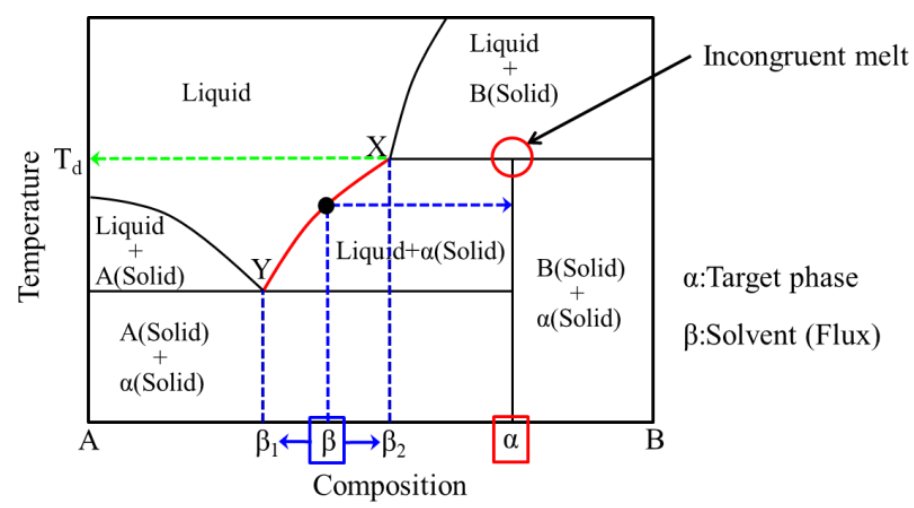

Figure 7. Typical phase diagram of an incongruently melting compound.

The TSFZ method is very effectual for single-crystal growth of high- $T_{\mathrm{c}}$ cuprate superconductors. Large (centimeter size) single crystals of high- $T_{\mathrm{c}}$ cuprate superconductors were successfully grown for the first time by the TSFZ method in [65]. For $\left(\mathrm{R}, \mathrm{A}_{\mathrm{e}}\right)-214$ single crystals, the solvent for the TSFZ method is the compounds with CuO-rich composition. For instance, a ( $\mathrm{La}, \mathrm{Sr})-214$ single crystal is grown from solvent of $\mathrm{CuO}$ with a composition from $78 \mathrm{~mol} \%$ [66], growth of (Nd,Ce)-214 single crystal also uses $\mathrm{CuO}$-rich solvent with $85 \mathrm{~mol} \% \mathrm{CuO}$ [67]. Figure 8 shows a $(\mathrm{Nd}, \mathrm{Ce})-214$ single crystal grown by TSFZ method. Single crystals of Bi-based high- $T_{\mathrm{c}}$ cuprate superconductors are also grown by the TSFZ method. For Bi-2212 single crystals, the nominal composition of the feed rod is $\mathrm{Bi}_{2.2} \mathrm{Sr}_{1.8} \mathrm{Ca}_{1.0} \mathrm{Cu}_{2.0} \mathrm{O}_{8}$, and that of the solvent is $\mathrm{Bi}_{2.4} \mathrm{Sr}_{1.5} \mathrm{Ca}_{1.0} \mathrm{Cu}_{1.8} \mathrm{O}_{x}$, which is Bi-rich and Sr-poor [68]. Bi-2223 has the highest $T_{\mathrm{C}}$ in Bi-based high- $T_{\mathrm{C}}$ cuprate superconductors. A Bi-2223 single crystal is grown by using a Bi-rich and Sr-poor feed rod and a very slow growth rate $(0.05 \mathrm{~mm} / \mathrm{h})$. Nominal composition of the Bi-rich and Sr-poor feed rod is $\mathrm{Bi}_{2.1} \mathrm{Sr}_{1.9} \mathrm{Ca}_{2.0} \mathrm{Cu}_{3.0} \mathrm{O}_{x}$ which plays a role as the solvent for the TSFZ method [69].

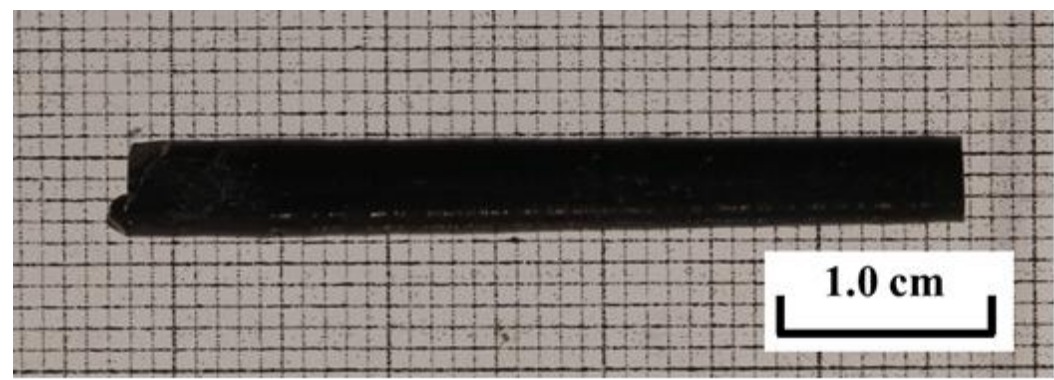

Figure 8. A (Nd,Ce)-214 single crystal grown by the TSFZ method. 


\subsection{Top-Seeded Solution Growth (TSSG) Method}

The op-seeded solution growth (TSSG) method is like a combination of the single-crystal growth technique for flux method and the Czochralski (CZ) method. A seed crystal is placed in the solution feed with a flux, and single crystals of the target material are slowly pulled from the bottom of the seed crystal. The schematic image of the TSSG method is shown in Figure 9. In the modified TSSG method, the temperature and/or concentration gradient are given between the top and bottom of the crucible [70].

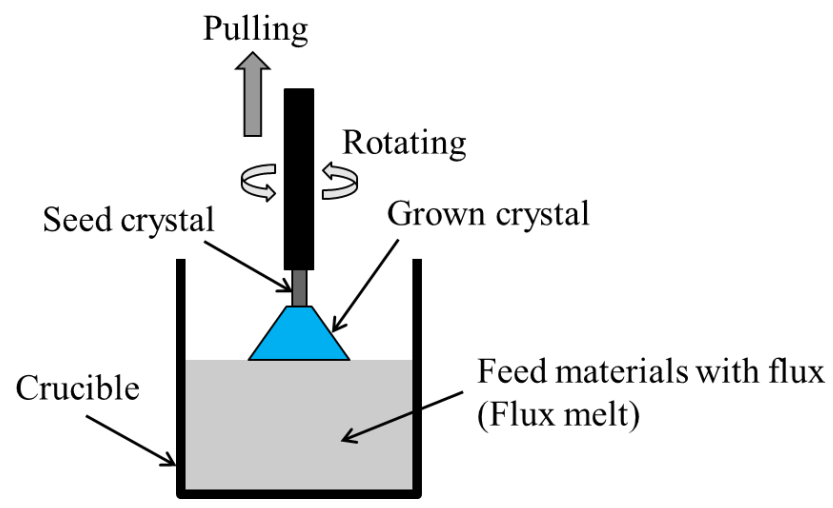

Figure 9. Schematic image of the top-seeded solution growth (TSSG) method.

(La,Ba)-214 single crystal is grown from a $\mathrm{CuO}$ flux solution of which the nominal composition of the solution is $\mathrm{La}(\mathrm{Ba})-214: \mathrm{CuO}=3: 17$ (molar ratio) [71]. Actually, the TSSG method mainly uses R-123 for single-crystal growth. Y-123 single crystals are grown from Y-123: $\mathrm{Ba}_{3} \mathrm{Cu}_{7} \mathrm{O}_{10}=17: 83$ (molar ratio) [72] and $\mathrm{Y}: \mathrm{Ba}: \mathrm{Cu}=5: 36: 59$ (cation ratio) [70] solution by the TSSG method. Additionally, $\mathrm{BaO} / \mathrm{CuO}$ flux is employed for $\mathrm{Nd}-123$ single-crystal growth, of which the nominal composition is $\mathrm{Nd}-123: \mathrm{Ba}_{3} \mathrm{Cu}_{5} \mathrm{O}_{8}=1: 3$ (molar ratio) [73].

\subsection{High-Temperature and High-Pressure (HPHT) Flux Method}

This flux method (See Section 2.1) is performed in a cubic anvil high-pressure apparatus under high-temperature and high-pressure (HPHT), which is named as the HPHT flux method. The typical schematic image of the sample cell assembly for the HPHT flux method is shown in Figure 10. This method is a powerful method for single-crystal growth. The HPHT flux method can avoid the vaporization from raw materials. Therefore, this method enables difficult single-crystal growth under ambient pressure. It can grow single crystals, not only layered superconductors, but also other superconductors. For instance, $\beta-\mathrm{ZrNCl}$ and $\beta-\mathrm{HfNCl}$ superconducting single crystals are grown using $\mathrm{NH}_{4} \mathrm{Cl}$ flux at $900-1200{ }^{\circ} \mathrm{C}$ under $3 \mathrm{GPa}$ [74]. $\mathrm{MgB}_{2}$ single crystals are successfully grown by the HPHT flux method $[75,76]$.

Some reports exhibit the single-crystal growth of Fe-based superconductors by the HPHT flux method. $\mathrm{L}_{n}(\mathrm{O}, \mathrm{F}) \mathrm{FeAs}\left(\mathrm{L}_{\mathrm{n}}=\mathrm{Pr}, \mathrm{Nd}, \mathrm{Sm}\right)$ single crystals are grown using NaAs or KAs flux by the HPHT flux method. The molar ratio of $\mathrm{L}_{n}(\mathrm{O}, \mathrm{F}) \mathrm{FeAs}$ raw materials and NaAs or KAs flux are weighed as between 1:1 and 1:10, respectively. That mixture puts in boron nitride $(\mathrm{BN})$ container, and then pressure is applied at $3 \mathrm{GPa}$. This anvil is heated for single-crystal growth. The remaining NaAs or KAs fluxes are dissolved in water [77]. By the same method, $\mathrm{NaCl} / \mathrm{KCl}$ flux is used for $\mathrm{Sm}(\mathrm{O}, \mathrm{F}) \mathrm{FeAs}$ single-crystal growth, and a nominal composition of $\mathrm{Sm}(\mathrm{O}, \mathrm{F}) \mathrm{FeAs}$ raw materials and $\mathrm{NaCl} / \mathrm{KCl}$ flux are between 1:1 and 1:3, respectively [78]. O-deficient SmOFeAs $\left(\mathrm{SmO}_{0.85} \mathrm{FeAs}\right)$ single crystals are grown from stoichiometric compound at 3.3 GPa, which is the HPHT self-flux method [79]. Furthermore, the HPHT flux method can also grow $\operatorname{Pr}(\mathrm{O}, \mathrm{F}) \mathrm{FeAs}$ single-crystalline whiskers. Flux is NaAs, and the molar ratio of $\operatorname{Pr}(\mathrm{O}, \mathrm{F}) \mathrm{FeAs}$ precursor to $\mathrm{NaAs}$ flux is $1: 1$, respectively. This mixture is put into a $\mathrm{BN}$ 
container and pressure is applied at $3 \mathrm{GPa}$. The product is heated and then whiskers with various lengths $(400-1300 \mu \mathrm{m})$, widths $(40-70 \mu \mathrm{m})$, and thicknesses $(5-10 \mu \mathrm{m})$ are obtained [80]. A review of single-crystal growth of Fe-based superconductors by the HPHT flux method is available in [81].

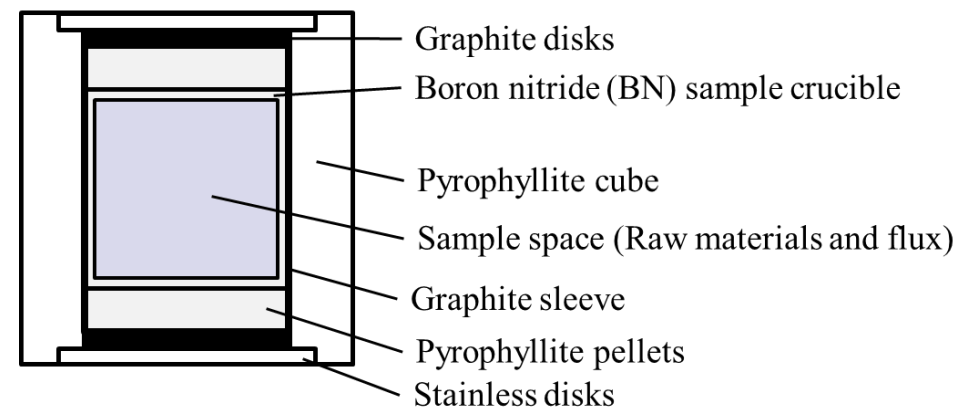

Figure 10. Schematic image of the sample cell assembly for the high-temperature and high-pressure (HPHT) flux method.

\section{Summary}

Flux is necessary for the growth of single crystals of layered superconductors. Small (mm size) single crystals can be grown by the conventional flux method. Low melting point metals (e.g., Sn), chloride-based compounds (e.g., $\mathrm{KCl}$ ) and self-flux are used for the flux. Furthermore, the particular flux can grow single-crystalline whiskers with perfect crystallinity. In contrast, large (cm size) single crystals are obtained by TSFZ and TSSG methods. The HPHT flux method makes single-crystal growth possible, which is difficult under ambient pressure.

Acknowledgments: The author would like to thank Akira Miura (Hokkaido University) for useful discussion and critical reading, and Isao Tanaka (University of Yamanashi) for providing the (Nd,Ce)-214 single crystal.

Conflicts of Interest: The author declares no conflict of interest.

\section{References}

1. Bednorz, J.G.; Müller, K.A. Possible high- $T_{\mathrm{c}}$ superconductivity in the Ba-La-Cu-O system. Z. Phys. B Condens. Matter 1986, 64, 189-193. [CrossRef]

2. Wu, M.K.; Ashburn, J.R.; Thorng, C.J.; Hor, P.H.; Meng, R.L.; Gao, L.; Huang, Z.J.; Wang, Y.Q.; Chu, C.W. Superconductivity at $93 \mathrm{~K}$ in a new mixed-phase $\mathrm{Y}-\mathrm{Ba}-\mathrm{Cu}-\mathrm{O}$ compound system at ambient pressure. Phys. Rev. Lett. 1987, 58, 908. [CrossRef] [PubMed]

3. Maeda, H.; Tanaka, Y.; Fukutomi, M.; Asano, T. A New High- $T_{\mathrm{c}}$ Oxide Superconductor without a Rare Earth Element. Jpn. J. Appl. Phys. 1988, 27, L209. [CrossRef]

4. Hidaka, Y.; Enomoto, Y.; Suzuki, M.; Oda, M.; Murakami, T. Single-crystal growth of $\left(\mathrm{La}_{1-x} \mathrm{~A}_{x}\right)_{2} \mathrm{CuO}_{4}$ $\left(\mathrm{A}=\mathrm{Ba}\right.$ or Sr) and $\mathrm{Ba}_{2} \mathrm{YCu}_{3} \mathrm{O}_{7-y}$. J. Cryst. Growth 1987, 85, 581-584. [CrossRef]

5. Asaoka, H.; Takei, H.; Iye, Y.; Tamura, M.; Kinoshita, M.; Takeya, H. Growth of Large Isometric $\mathrm{YBa}_{2} \mathrm{Cu}_{3} \mathrm{O}_{x}$ Single Crystals from Coexisting Region of Solid with Melt in $\mathrm{Y}_{2} \mathrm{O}_{3}$ Crucibles. Jpn. J. Appl. Phys. 1993, 32, 1091. [CrossRef]

6. Funabiki, H.; Okanoue, K.; Takano, C.; Hamasaki, K. Growth conditions and characterization of $\mathrm{Bi}_{2} \mathrm{Sr}_{2} \mathrm{CaCu}_{2} \mathrm{O}_{8+\delta}$ single crystals. J. Cryst. Growth 2003, 259, 85-89. [CrossRef]

7. Gencer, F.; Abell, J.S. The growth of $\mathrm{YBa}_{2} \mathrm{Cu}_{3} \mathrm{O}_{7-\delta}$ single crystals with the aid of $\mathrm{NaCl}-\mathrm{KCl}$ flux. J. Cryst. Growth 1991, 112, 337-342. [CrossRef]

8. Katsui, A. Crystal Growth of Superconducting Bi-Sr-Ca-Cu-O Compounds from $\mathrm{KCl}$ Solution. Jpn. J. Appl. Phys. 1988, 27, L844. [CrossRef]

9. Wang, X.L.; Horvat, J.; Liu, H.K.; Dou, S.X. Spiral growth of $\mathrm{Bi}_{2} \mathrm{Sr}_{2} \mathrm{CaCu}_{2} \mathrm{O}_{y}$ single crystals using $\mathrm{KCl}$ flux technique. J. Cryst. Growth 1997, 173, 380-385. [CrossRef]

10. Lee, S.; Yamamoto, A.; Tajima, S. Crystal growth of $\mathrm{Bi}_{2} \mathrm{Sr}_{2} \mathrm{Ca}_{2} \mathrm{Cu}_{3} \mathrm{O}_{10+x}$ and $(\mathrm{Bi}, \mathrm{Pb})_{2} \mathrm{Sr}_{2} \mathrm{Ca}_{2} \mathrm{Cu}_{3} \mathrm{O}_{10+x}$ by the $\mathrm{KCl}$ flux method. J. Mater. Res. 2002, 17, 2286-2293. [CrossRef] 
11. Matsubara, I.; Kageyama, H.; Tanigawa, H.; Okura, T.; Yamashita, H.; Kawai, T. Preparation of Fibrous $\mathrm{Bi}(\mathrm{Pb})-\mathrm{Sr}-\mathrm{Ca}-\mathrm{Cu}-\mathrm{O}$ Crystals and Their Superconducting Properties in a Bending State. Jpn. J. Appl. Phys. 1989, 28, L1121. [CrossRef]

12. Nagao, M.; Sato, M.; Maeda, H.; Kim, S.J.; Yamashita, T. Growth and superconducting properties of $\mathrm{Bi}_{2} \mathrm{Sr}_{2} \mathrm{CaCu}_{2} \mathrm{O}_{8+\delta}$ single-crystal whiskers using tellurium-doped precursors. Appl. Phys. Lett. 2001, 79, 2612-2614. [CrossRef]

13. Nagao, M.; Sato, M.; Maeda, H.; Kim, S.J.; Yamashita, T. Growth and electrical transport characteristics of $\mathrm{Bi}_{2} \mathrm{Sr}_{2} \mathrm{Ca}_{1} \mathrm{Cu}_{2} \mathrm{O}_{x}$ and $\mathrm{Bi}_{2} \mathrm{Sr}_{2} \mathrm{CuO}_{x}$ single-crystal whiskers using tellurium-doped precursors. Phys. C 2002, 377, 260-266. [CrossRef]

14. Nagao, M.; Sato, M.; Maeda, H.; Kim, S.J.; Yamashita, T. Growth and Superconductivity of $(\mathrm{BiPb})_{2} \mathrm{Sr}_{2} \mathrm{Ca}_{2} \mathrm{Cu}_{3} \mathrm{O}_{10+\delta}$ Single-Crystal Whiskers. Jpn. J. Appl. Phys. 2002, 41, L43. [CrossRef]

15. Nagao, M.; Watauchi, S.; Tanaka, I.; Okutsu, T.; Takano, Y.; Hatano, T.; Maeda, H. Growth and Anisotropic Properties of $\mathrm{RBa}_{2} \mathrm{Cu}_{3} \mathrm{O}_{x}$ Single-Crystal Whiskers. Jpn. J. Appl. Phys. 2010, 49. [CrossRef]

16. Nagao, M.; Yun, K.S.; Nakane, T.; Wang, H.; Takano, Y.; Hatano, T.; Yamashita, T.; Tachiki, M.; Maeda, H.; Sato, M. Growth of $\mathrm{Y}_{1} \mathrm{Ba}_{2} \mathrm{Cu}_{3} \mathrm{O}_{x}$ Single-Crystal Whisker Using Sb-doped Precursor. Jpn. J. Appl. Phys. 2005, 44, L67. [CrossRef]

17. Nagao, M.; Kawae, T.; Yun, K.S.; Wang, H.; Takano, Y.; Hatano, T.; Yamashita, T.; Tachiki, M.; Maeda, H.; Sato, M. Intrinsic Josephson junctions in $\mathrm{Y}_{1} \mathrm{Ba}_{2} \mathrm{Cu}_{3} \mathrm{O}_{x}$ single-crystal whiskers grown using Te-doped precursors. J. Appl. Phys. 2005, 98, 073903. [CrossRef]

18. Nagao, M.; Sato, M.; Maeda, H.; Yun, K.S.; Takano, Y.; Hatano, T.; Kim, S.J. Superconducting properties of single-crystal whiskers of $\left(\mathrm{Y}_{0.86} \mathrm{Ca}_{0.14}\right) \mathrm{Ba}_{2} \mathrm{Cu}_{3} \mathrm{O}_{x}$ grown from precursors containing calcium and tellurium. Appl. Phys. Lett. 2003, 82, 1899-1901. [CrossRef]

19. Nagao, M.; Sato, M.; Tachiki, Y.; Miyagawa, K.; Tanaka, M.; Maeda, H.; Yun, K.S.; Takano, Y.; Hatano, T. Growth of R-123 Phase Single Crystal Whiskers. Jpn. J. Appl. Phys. 2004, 43, L324. [CrossRef]

20. Deguchi, K.; Ogawara, S.; Okutsu, T.; Nagao, M.; Watanabe, T.; Mizuguchi, Y.; Kubo, Y.; Tomioka, F.; Ishii, S.; Tsuda, S.; et al. Growth of superconducting single-crystalline ( $\mathrm{Lu}, \mathrm{Ca}) \mathrm{Ba}_{2} \mathrm{Cu}_{3} \mathrm{O}_{7-\delta}$ whiskers. Phys. C 2009, 469, 965-966. [CrossRef]

21. Kamihara, Y.; Watanabe, T.; Hirano, M.; Hosono, H. Iron-Based Layered Superconductor La[O $\left.{ }_{1-x} \mathrm{~F}_{\mathrm{x}}\right] \mathrm{Fe} A s$ $(x=0.05-0.12)$ with $T_{\mathrm{c}}=26 \mathrm{~K} . \mathrm{J}$. Am. Chem. Soc. 2008, 130, 3296-3297. [CrossRef] [PubMed]

22. Rotter, M.; Tegel, M.; Johrendt, D. Superconductivity at $38 \mathrm{~K}$ in the Iron Arsenide $\left(\mathrm{Ba}_{1-x} \mathrm{~K}_{x}\right) \mathrm{Fe}_{2} \mathrm{As}_{2}$. Phys. Rev. Lett. 2008, 101, 107006. [CrossRef] [PubMed]

23. Tapp, J.H.; Tang, Z.; Lv, B.; Sasmal, K.; Lorenz, B.; Chu, P.C.W.; Guloy, A.M. LiFeAs: An intrinsic FeAs-based superconductor with $T_{\mathrm{C}}=18 \mathrm{~K}$. Phys. Rev. B 2008, 78. [CrossRef]

24. Hsu, F.C.; Luo, J.Y.; Yeh, K.W.; Chen, T.K.; Huang, T.W.; Wu, P.M.; Lee, Y.C.; Huang, Y.L.; Chu, Y.Y.; Yan, D.C.; et al. Superconductivity in the PbO-type structure $\alpha$-FeSe. Proc. Natl. Acad. Sci. USA 2008, 105, 14262-14264. [CrossRef] [PubMed]

25. Guo, J.; Jin, S.; Wang, G.; Wang, S.; Zhu, K.; Zhou, T.; He, M.; Chen, X. Superconductivity in the iron selenide $\mathrm{K}_{x} \mathrm{Fe}_{2} \mathrm{Se}_{2}(0 \leq x \leq 1.0)$. Phys. Rev. B 2010, 82, 180520. [CrossRef]

26. Ogino, H.; Matsumura, Y.; Katsura, Y.; Ushiyama, K.; Horii, S.; Kishio, K.; Shimoyama, J. Superconductivity at $17 \mathrm{~K}$ in $\left(\mathrm{Fe}_{2} \mathrm{P}_{2}\right)\left(\mathrm{Sr}_{4} \mathrm{Sc}_{2} \mathrm{O}_{6}\right)$ : A new superconducting layered pnictide oxide with a thick perovskite oxide layer. Supercond. Sci. Technol. 2009, 22. [CrossRef]

27. Luo, H.; Wang, Z.; Yang, H.; Cheng, P.; Zhu, X.; Wen, H.H. Growth and characterization of $\mathrm{A}_{1-x} \mathrm{~K}_{x} \mathrm{Fe}_{2} \mathrm{As}_{2}$ $(\mathrm{A}=\mathrm{Ba}$, Sr) single crystals with $x=0-0.4$. Supercond. Sci. Technol. 2008, 21, 125014. [CrossRef]

28. Chen, G.F.; Li, Z.; Dong, J.; Li, G.; Hu, W.Z.; Zhang, X.D.; Song, X.H.; Zheng, P.; Wang, N.L.; Luo, J.L. Transport and anisotropy in single-crystalline $\mathrm{SrFe}_{2} \mathrm{As}_{2}$ and $\mathrm{A}_{0.6} \mathrm{~K}_{0.4} \mathrm{Fe}_{2} \mathrm{As}_{2}(\mathrm{~A}=\mathrm{Sr}, \mathrm{Ba}$ ) superconductors. Phys. Rev. B 2008, 78, 224512. [CrossRef]

29. Kihou, K.; Saito, T.; Ishida, S.; Nakajima, M.; Tomioka, Y.; Fukazawa, H.; Kohori, Y.; Ito, T.; Uchida, S.; Iyo, A.; et al. Single-crystal growth and Characterization of the Iron-Based Superconductor $\mathrm{KFe}_{2} \mathrm{As}_{2}$ Synthesized by KAs Flux Method. J. Phys. Soc. Jpn. 2010, 79, 124713. [CrossRef]

30. Wang, C.; Gao, Z.; Yao, C.; Wang, L.; Qi, Y.; Wang, D.; Zhang, X.; Ma, Y. One-step method to grow $\mathrm{Ba}_{0.6} \mathrm{~K}_{0.4} \mathrm{Fe}_{2} \mathrm{As}_{2}$ single crystals without fluxing agent. Supercond. Sci. Technol. 2011, 24. [CrossRef] 
31. Morozov, I.; Boltalin, A.; Volkova, O.; Vasiliev, A.; Kataeva, O.; Stockert, U.; Abdel-Hafiez, M.; Bombor, D.; Bachmann, A.; Harnagea, L.; et al. Single-crystal growth and Characterization of Superconducting LiFeAs. Cryst. Growth Des. 2010, 10, 4428-4432. [CrossRef]

32. Wang, A.F.; Luo, X.G.; Yan, Y.J.; Ying, J.J.; Xiang, Z.J.; Ye, G.J.; Cheng, P.; Li, Z.Y.; Hu, W.J.; Chen, X.H. Phase diagram and calorimetric properties of $\mathrm{NaFe}_{1-x} \mathrm{Co} x$ As. Phys. Rev. B 2012, 85, 224521. [CrossRef]

33. Moll, P.J.W.; Zhu, X.; Cheng, P.; Wen, H.H.; Batlogg, B. Intrinsic Josephson junctions in the iron-based multi-band superconductor $\left(\mathrm{V}_{2} \mathrm{Sr}_{4} \mathrm{O}_{6}\right) \mathrm{Fe}_{2} \mathrm{As}_{2}$. Nat. Phys. 2014, 10, 644-647. [CrossRef]

34. Li, J.; Yuan, J.; Tang, D.M.; Zhang, S.B.; Li, M.Y.; Guo, Y.F.; Tsujimoto, Y.; Hatano, T.; Arisawa, S.; Golberg, D.; et al. Growth of Single-Crystal $\mathrm{Ca}_{10}\left(\mathrm{Pt}_{4} \mathrm{As}_{8}\right)\left(\mathrm{Fe}_{1.8} \mathrm{Pt}_{0.2} \mathrm{As}_{2}\right)_{5}$ Nanowhiskers with Superconductivity up to 33 K. J. Am. Chem. Soc. 2012, 134, 4068-4071. [CrossRef] [PubMed]

35. Ni, N.; Bud'ko, S.L.; Kreyssig, A.; Nandi, S.; Rustan, G.E.; Goldman, A.I.; Gupta, S.; Corbett, J.D.; Kracher, A.; Canfield, P.C. Anisotropic thermodynamic and transport properties of single-crystalline $\mathrm{Ba}_{1-x} \mathrm{~K}_{x} \mathrm{Fe}_{2} \mathrm{As}_{2}(x=$ 0 and 0.45). Phys. Rev. B 2008, 78. [CrossRef]

36. Bukowski, Z.; Weyeneth, S.; Puzniak, R.; Moll, P.; Katrych, S.; Zhigadlo, N.D.; Karpinski, J.; Keller, H.; Batlogg, B. Superconductivity at $23 \mathrm{~K}$ and low anisotropy in Rb-substituted $\mathrm{BaFe}_{2} \mathrm{As}_{2}$ single crystals. Phys. Rev. B 2009, 79, 104521. [CrossRef]

37. Hu, R.; Lei, H.; Abeykoon, M.; Bozin, E.S.; Billinge, S.J.L.; Warren, J.B.; Siegrist, T.; Petrovic, C. Synthesis, crystal structure, and magnetism of $\beta-\mathrm{Fe}_{1.00(2)} \mathrm{Se}_{1.00(3)}$ single crystals. Phys. Rev. B 2011, 83, 224502. [CrossRef]

38. Böhmer, A.E.; Hardy, F.; Eilers, F.; Ernst, D.; Adelmann, P.; Schweiss, P.; Wolf, T.; Meingast, C. Lack of coupling between superconductivity and orthorhombic distortion in stoichiometric single-crystalline FeSe. Phys. Rev. B 2013, 87, 180505. [CrossRef]

39. Zhang, S.B.; Sun, Y.P.; Zhu, X.D.; Zhu, X.B.; Wang, B.S.; Li, G.; Lei, H.C.; Luo, X.; Yang, Z.R.; Song, W.H.; et al. Crystal growth and superconductivity of FeSe $e_{x}$. Supercond. Sci. Technol. 2009, 22. [CrossRef]

40. Mizuguchi, Y.; Fujihisa, H.; Gotoh, Y.; Suzuki, K.; Usui, H.; Kuroki, K.; Demura, S.; Takano, Y.; Izawa, H.; Miura, O. $\mathrm{BiS}_{2}$-based layered superconductor $\mathrm{Bi}_{4} \mathrm{O}_{4} \mathrm{~S}_{3}$. Phys. Rev. B 2012, 86, 220510. [CrossRef]

41. Mizuguchi, Y.; Demura, S.; Deguchi, K.; Takano, Y.; Fujihisa, H.; Gotoh, Y.; Izawa, H.; Miura, O. Superconductivity in Novel $\mathrm{BiS}_{2}$-Based Layered Superconductor $\mathrm{LaO}_{1-x} \mathrm{~F}_{x} \mathrm{BiS}_{2}$. J. Phys. Soc. Jpn. 2012, 81, 114725. [CrossRef]

42. Xing, J.; Li, S.; Ding, X.; Yang, H.; Wen, H.H. Superconductivity appears in the vicinity of semiconducting-like behavior in $\mathrm{CeO}_{1-x} \mathrm{~F}_{x} \mathrm{BiS}_{2}$. Phys. Rev. B 2012, 86, 214518. [CrossRef]

43. Jha, R.; Kumar, A.; Singh, S.K.; Awana, V.P.S. Synthesis and Superconductivity of New $\mathrm{BiS}_{2} \mathrm{Based}^{-}$ Superconductor $\mathrm{PrO}_{0.5} \mathrm{~F}_{0.5} \mathrm{BiS}_{2}$. J. Supercond. Novel Magn. 2013, 26, 499-502. [CrossRef]

44. Demura, S.; Mizuguchi, Y.; Deguchi, K.; Okazaki, H.; Hara, H.; Watanabe, T.; Denholme, S.J.; Fujioka, M.; Ozaki, T.; Fujihisa, H.; et al. New Member of $\mathrm{BiS}_{2}$-Based Superconductor $\mathrm{NdO}_{1-x} \mathrm{~F}_{x} \mathrm{BiS}_{2}$. J. Phys. Soc. Jpn. 2013, 82. [CrossRef]

45. Yazici, D.; Huang, K.; White, B.D.; Chang, A.H.; Friedman, A.J.; Maple, M.B. Superconductivity of F-substituted $\mathrm{LnOBiS}_{2}$ (Ln = La, Ce, Pr, Nd, Yb) compounds. Philos. Mag. 2013, 93, 673-680. [CrossRef]

46. Lin, X.; Ni, X.; Chen, B.; Xu, X.; Yang, X.; Dai, J.; Li, Y.; Yang, X.; Luo, Y.; Tao, Q.; et al. Superconductivity induced by La doping in $\mathrm{Sr}_{1-x} \mathrm{La}_{x} \mathrm{FBiS}_{2}$. Phys. Rev. B 2013, 87. [CrossRef]

47. Lei, H.C.; Wang, K.F.; Abeykoon, M.; Bozin, E.S.; Petrovic, C. New Layered Fluorosulfide SrFBiS 2 . Inorg. Chem. 2013, 52, 10685-10689. [CrossRef] [PubMed]

48. Zhai, H.F.; Tang, Z.T.; Jiang, H.; Xu, K.; Zhang, K.; Zhang, P.; Bao, J.K.; Sun, Y.L.; Jiao, W.H.; Nowik, I.; et al. Possible charge-density wave, superconductivity, and f-electron valence instability in $\mathrm{EuBiS}_{2}$ F. Phys. Rev. B 2014, 90. [CrossRef]

49. Yazici, D.; Huang, K.; White, B.D.; Jeon, I.; Burnett, V.W.; Friedman, A.J.; Lum, I.K.; Nallaiyan, M.; Spagna, S.; Maple, M.B. Superconductivity induced by electron doping in $\mathrm{La}_{1-x} \mathrm{M}_{x} \mathrm{OBiS}_{2}(\mathrm{M}=\mathrm{Ti}, \mathrm{Zr}, \mathrm{Hf}, \mathrm{Th})$. Phys. Rev. B 2013, 87, 174512. [CrossRef]

50. Zhai, H.F.; Zhang, P.; Wu, S.Q.; He, C.Y.; Tang, Z.T.; Jiang, H.; Sun, Y.L.; Bao, J.K.; Nowik, I.; Felner, I.; et al. Anomalous Eu Valence State and Superconductivity in Undoped $\mathrm{Eu}_{3} \mathrm{Bi}_{2} \mathrm{~S}_{4} \mathrm{~F}_{4}$. J. Am. Chem. Soc. 2014, 136, 15386-15393. [CrossRef] [PubMed]

51. Shao, J.; Yao, X.; Liu, Z.; Pi, L.; Tan, S.; Zhang, C.; Zhang, Y. Superconductivity in $\mathrm{BiO}_{1-x} \mathrm{~F}_{x} \mathrm{BiS}_{2}$ and possible parent phase of $\mathrm{Bi}_{4} \mathrm{O}_{4} \mathrm{~S}_{3}$ superconductor. Supercond. Sci. Technol. 2015, 28. [CrossRef] 
52. Okada, T.; Ogino, H.; Shimoyama, J.; Kishio, K. Topotactic synthesis of a new $\mathrm{BiS}_{2}$-based superconductor $\mathrm{Bi}_{2}(\mathrm{O}, \mathrm{F}) \mathrm{S}_{2}$. Appl. Phys. Express 2015, 8. [CrossRef]

53. Krzton-Maziopa, A.; Guguchia, Z.; Pomjakushina, E.; Pomjakushin, V.; Khasanov, R.; Luetkens, H.; Biswas, P.; Amato, A.; Keller, H.; Conder, K. Superconductivity in a new layered bismuth oxyselenide: $\mathrm{LaO}_{0.5} \mathrm{~F}_{0.5} \mathrm{BiSe}_{2}$. J. Phys. Condens. Matter 2014, 26, 215702. [CrossRef] [PubMed]

54. FTsalt-FACT Salt Phase Diagrams (CsCl-KCl). Available online: http://www.crct.polymtl.ca/fact/phase_ diagram.php?file=CsCl-KCl.jpg\&dir=FTsalt (accessed on 16 October 2017).

55. Nagao, M.; Demura, S.; Deguchi, K.; Miura, A.; Watauchi, S.; Takei, T.; Takano, Y.; Kumada, N.; Tanaka, I. Structural Analysis and Superconducting Properties of F-Substituted NdOBiS 2 Single Crystals. J. Phys. Soc. Jpn. 2013, 82, 113701. [CrossRef]

56. Nagao, M.; Miura, A.; Demura, S.; Deguchi, K.; Watauchi, S.; Takei, T.; Takano, Y.; Kumada, N.; Tanaka, I. Growth and superconducting properties of F-substituted $\mathrm{ROBiS}_{2}(\mathrm{R}=\mathrm{La}, \mathrm{Ce}, \mathrm{Nd})$ single crystals. Solid State Commun. 2014, 178, 33-36. [CrossRef]

57. Higashinaka, R.; Asano, T.; Nakashima, T.; Fushiya, K.; Mizuguchi, Y.; Miura, O.; Matsuda, T.D.; Aoki, Y. Pronounced-Log T Divergence in Specific Heat of Nonmetallic CeOBiS 2 : A Mother Phase of BiS 2 -Based Superconductor. J. Phys. Soc. Jpn. 2015, 84. [CrossRef]

58. Nagao, M.; Miura, A.; Ueta, I.; Watauchi, S.; Tanaka, I. Superconductivity in $\mathrm{CeOBiS}_{2}$ with cerium valence fluctuation. Solid State Commun. 2016, 245, 11-14. [CrossRef]

59. Nagao, $\mathrm{M}$. Growth and characterization of $\mathrm{R}(\mathrm{O}, \mathrm{F}) \mathrm{BiS}_{2}(\mathrm{R}=\mathrm{La}, \mathrm{Ce}, \mathrm{Pr}, \mathrm{Nd})$ superconducting single crystals. Nov. Supercond. Mater. 2015, 1, 64-74. [CrossRef]

60. Liu, J.; Fang, D.; Wang, Z.; Xing, J.; Du, Z.; Li, S.; Zhu, X.; Yang, H.; Wen, H.H. Giant superconducting fluctuation and anomalous semiconducting normal state in $\mathrm{NdO}_{1-x} \mathrm{~F}_{x} \mathrm{Bi}_{1-y} \mathrm{~S}_{2}$ single crystals. Europhys. Lett. 2014, 106, 67002. [CrossRef]

61. Nagao, M.; Tanaka, M.; Watauchi, S.; Tanaka, I.; Takano, Y. Superconducting Anisotropies of F-Substituted $\mathrm{LaOBiSe}_{2}$ Single Crystals. J. Phys. Soc. Jpn. 2014, 83, 114709. [CrossRef]

62. Nagao, M.; Tanaka, M.; Matsumoto, R.; Tanaka, H.; Watauchi, S.; Takano, Y.; Tanaka, I. Growth and Structure of $\mathrm{Ce}(\mathrm{O}, \mathrm{F}) \mathrm{SbS}_{2}$ Single Crystals. Cryst. Growth Des. 2016, 16, 3037-3042. [CrossRef]

63. Kimura, S.; Shindo, I. Single-crystal growth of YIG by the floating zone method. J. Cryst. Growth 1977, 41, 192-198. [CrossRef]

64. Koohpayeh, S.M. Single-crystal growth by the traveling solvent technique: A review. Prog. Cryst. Growth Charact. Mater. 2016, 62, 22-34. [CrossRef]

65. Tanaka, I.; Kojima, H. Superconducting single crystals. Nature 1988, 337, 21-22. [CrossRef]

66. Tanaka, I.; Yamane, K.; Kojima, H. Single-crystal growth of superconducting $\mathrm{La}_{2-x} \mathrm{Sr}_{x} \mathrm{CuO}_{4}$ by the TSFZ method. J. Cryst. Growth 1989, 96, 711-715. [CrossRef]

67. Tanaka, I.; Watanabe, T.; Komai, N.; Kojima, H. Growth and superconductivity of $\mathrm{Nd}_{2-x} \mathrm{Ce}_{x} \mathrm{CuO}_{4}$ single crystals. Physica C 1991, 185-189, 437-438. [CrossRef]

68. Takekawa, S.; Nozaki, H.; Umezono, A.; Kosuda, K.; Kobayashi, M. Single-crystal growth of the superconductor $\mathrm{Bi}_{2.0}\left(\mathrm{Bi}_{0.2} \mathrm{Sr}_{1.8} \mathrm{Ca}_{1.0}\right) \mathrm{Cu}_{2.0} \mathrm{O}_{8}$. J. Cryst. Growth 1988, 92, 687-690. [CrossRef]

69. Fujii, T.; Watanabe, T.; Matsuda, A. Single-crystal growth of $\mathrm{Bi}_{2} \mathrm{Sr}_{2} \mathrm{Ca}_{2} \mathrm{Cu}_{3} \mathrm{O}_{10+\delta}$ (Bi-2223) by TSFZ method. J. Cryst. Growth 2001, 223, 175-180. [CrossRef]

70. Yamada, Y.; Shiohara, Y. Continuous crystal growth of $\mathrm{YBa}_{2} \mathrm{Cu}_{3} \mathrm{O}_{7-x}$ by the modified top-seeded crystal pulling method. Physica C 1993, 217, 182-188. [CrossRef]

71. Rytz, D.; Wechsler, B.A.; Nelson, C.C.; Kirby, K.W. Top-seeded solution growth of $\mathrm{BaTiO}_{3}, \mathrm{KNbO}_{3}, \mathrm{SrTiO}_{3}$, $\mathrm{Bi}_{12} \mathrm{TiO}_{20}$ and $\mathrm{La}_{2-x}, \mathrm{Ba}_{x} \mathrm{CuO}_{4}$. J. Cryst. Growth 1990, 99, 864-868. [CrossRef]

72. Zhokhov, A.A.; Emel'chenko, G.A. Growth of $\mathrm{YBa}_{2} \mathrm{Cu}_{3} \mathrm{O}_{7-\delta}$ single crystals on seeds by a modified top seeded solution growth (TSSG) technique. J. Cryst. Growth 1993, 129, 786-788. [CrossRef]

73. Oka, K.; Unoki, H. Primary crystallization fields and crystal growth of $\mathrm{YBa}_{2} \mathrm{Cu}_{3} \mathrm{O}_{7-y}$ and $\mathrm{NdBa}_{2} \mathrm{Cu}_{3} \mathrm{O}_{7-y}$. J. Cryst. Growth 1990, 99, 922-924. [CrossRef]

74. Chen, X.; Koiwasaki, T.; Yamanaka, S. High-Pressure Synthesis and Crystal Structures of $\beta-\mathrm{MNCl}(\mathrm{M}=\mathrm{Zr}$ and Hf). J. Solid State Chem. 2001, 159, 80-86. [CrossRef]

75. Karpinski, J.; Angst, M.; Jun, J.; Kazakov, S.M.; Puzniak, R.; Wisniewski, A.; Roos, J.; Keller, H.; Perucchi, A.; Degiorgi, L.; et al. $\mathrm{MgB}_{2}$ single crystals: High pressure growth and physical properties. Supercond. Sci. Technol. 2003, 16, 221. [CrossRef] 
76. Karpinski, J.; Zhigadlo, N.D.; Katrych, S.; Puzniak, R.; Rogacki, K.; Gonnelli, R. Single crystals of MgB : $_{2}$ Synthesis, substitutions and properties. Physica C 2007, 456, 3-13. [CrossRef]

77. Zhigadlo, N.D.; Weyeneth, S.; Katrych, S.; Moll, P.J.W.; Rogacki, K.; Bosma, S.; Puzniak, R.; Karpinski, J.; Batlogg, B. High-pressure flux growth, structural, and superconducting properties of $\mathrm{LnFeAsO}(\mathrm{Ln}=\mathrm{Pr}, \mathrm{Nd}$, Sm) single crystals. Phys. Rev. B 2012, 86, 214509. [CrossRef]

78. Zhigadlo, N.D.; Katrych, S.; Bukowski, Z.; Weyeneth, S.; Puzniak, R.; Karpinski, J. Single crystals of superconducting $\mathrm{SmFeAsO}_{1-} \mathrm{F}_{y}$ grown at high pressure. J. Phys. Condens. Matter 2008, 20, 342202. [CrossRef]

79. Lee, H.S.; Park, J.H.; Lee, J.Y.; Kim, J.Y.; Sung, N.H.; Koo, T.Y.; Cho, B.K.; Jung, C.U.; Saini, S.; Kim, S.J.; et al. High-pressure growth of fluorine-free $\mathrm{SmFeAsO}_{1-x}$ superconducting single crystals. Supercond. Sci. Technol. 2009, 22. [CrossRef]

80. Zhigadlo, N.D. Growth of whisker-like and bulk single crystals of $\operatorname{PrFeAs}(\mathrm{O}, \mathrm{F})$ under high pressure. J. Cryst. Growth 2013, 382, 75-79. [CrossRef]

81. Karpinski, J.; Zhigadlo, N.D.; Katrych, S.; Bukowski, Z.; Moll, P.; Weyeneth, S.; Keller, H.; Puzniak, R.; Tortello, M.; Daghero, D; et al. Single crystals of $\mathrm{LnFeAsO}_{1-x} \mathrm{~F}_{x}(\mathrm{Ln}=\mathrm{La}, \mathrm{Pr}, \mathrm{Nd}, \mathrm{Sm}, \mathrm{Gd})$ and

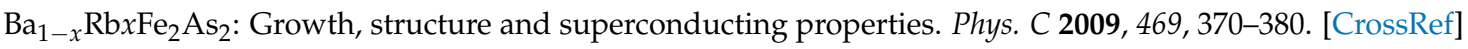

(C) 2017 by the author. Licensee MDPI, Basel, Switzerland. This article is an open access article distributed under the terms and conditions of the Creative Commons Attribution (CC BY) license (http://creativecommons.org/licenses/by/4.0/). 